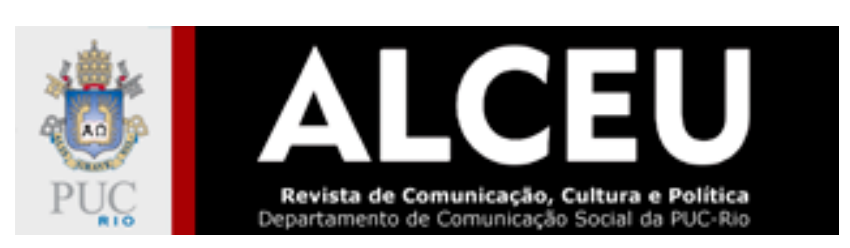

\title{
Direito à comunicação e ativismo feminista:
}

\section{A construção de redes de mulheres na América Latina e o processo de apropriação tecnológica}

\section{Por Karina Janz Woitowicz}

\author{
Introdução
}

Ao longo da trajetória do movimento feminista, a comunicação esteve presente como forma de difundir interna e/ou externamente os ideais do movimento, promover campanhas e denunciar a opressão às mulheres e como parte do próprio processo de organização e mobilização.

Dos jornais e revistas feministas publicados no século XIX e início do século XX por pioneiras do feminismo em diferentes países da América Latina às experiências de comunicação popular e comunitária, principalmente em rádios, realizadas por distintos grupos de mulheres, a utilização de meios de comunicação pelos grupos feministas se insere em suas estratégias de luta como mecanismo de visibilidade pública que se acentua no século XXI. De acordo com Márquez (2017, p. 187-188), os meios comunitários "contribuyen y favorecen la participación de la comunicación y favorecen el debate, de manera que se convierten en canales estratégicos para el ejercicio de ciudadanía de mujeres que, incluso en los sectores populares, encuentran más dificultades que los varones para disfrutar de sus derechos".

Nos anos 1990 se tem registro de redes de organizações que passaram a utilizar a internet (inicialmente, iniciativas que se concentravam no uso do correio eletrônico para difundir informações) para estabelecer debates sobre temas de interesse e manter vínculos. Desde então, o movimento feminista percebeu a potencialidade das tecnologias como ferramenta de articulação política e estratégia para promoção e visibilidade das suas lutas. 
A principios de la década de los noventa, Internet demostró las oportunidades de la red para la comunicación de las organizaciones de diferentes países que preparaban los trabajos de la Cuarta Conferencia Mundial de la Mujer. Además, la red permitió la difusión de informaciones desde el encuentro, que pudieron ser distribuidas sin pasar por el filtro de las agencias informativas. (MÁRQUEZ, 2017, p. 188) ${ }^{1}$

Natansohn (2013, p. 28) observa que a herança do ciberfeminismo dos anos 1990 está criando um novo processo de participação das mulheres, "especialmente atrativo para as mulheres mais jovens, crescidas no ambiente digital, cujo vínculo com o feminismo tradicional é desfavorecido pela brecha cultural, digital e geracional".

Percebe-se, assim, a importância de "tomar a palavra" para demarcar as lutas feministas, em um processo que acentua as iniciativas de mobilização popular envolvendo as mulheres que marcaram as ditaduras na América Latina desde os anos 1960 e a gradual abertura política, vivenciada na maior parte dos países da região entre os anos 1980 e 90. As possibilidades de intervenção no espaço público por meio das mídias digitais, mesmo considerando assimetrias de acesso e de condições de produção (CERQUEIRA; RIBEIRO; CABECINHAS, 2009), revelam que a internet "possui inegáveis potencialidades para a afirmação das vozes femininas, contudo não pode ser encarada de forma linear como a solução para o problema persistente da desigualdade de gênero" (p. 121). Entende-se que a ocupação de espaços de atuação política no campo da mídia, ao demandar um novo tipo de apropriação da cultura digital por parte de feministas, contribui para tensionar as relações de poder e inserir determinadas demandas na agenda pública.

O presente artigo, ao colocar em pauta a trajetória de apropriação das tecnologias pelos movimentos de mulheres que reivindicam o direito à comunicação, com base na bibliografia sobre o tema e documentos elaborados em conferências de mulheres, busca situar alguns marcos desta história recente e, ao mesmo tempo, refletir sobre os impactos do desenvolvimento da web no fortalecimento de iniciativas de mídia alternativa com perspectiva feminista na América Latina.

\footnotetext{
1 Márquez (2017, p. 188) destaca iniciativas pioneiras que marcaram este período, como o portal Mujeres en Red, periódicos feministas e, mais recentemente, Wikimujeres.
} 


\section{Comunicação e direitos das mulheres: uma trajetória}

A Conferência Mundial da Mulher (Beijing, 1995), em sua Plataforma de Ação (ponto J, sobre mulheres e mídia) ${ }^{2}$, assinala um marco importante no que diz respeito às mulheres e aos meios de comunicação, ao destacar o acesso aos meios e a promoção de uma imagem equilibrada e não estereotipada na mídia como alternativas para diminuir as desigualdades. ${ }^{3}$ Trata-se de entender a comunicação como uma esfera dos direitos humanos e como um elemento estratégico para promover a participação social das mulheres.

Sabe-se, contudo, que, muito antes de ser referendada em Pequim como um campo importante para a conquista da igualdade entre homens e mulheres, a comunicação já era não apenas feita como também refletida e teorizada enquanto um espaço onde se processam as lutas das mulheres. $O$ documento apresentado no seminário "La Comunicación Alternativa de la Mujer en América Latina" - que aconteceu no México em 1982 e foi o marco para a criação da revista Fempress -, elaborado por Adriana Santa Cruz e Viviana Erazo, apresenta os princípios de uma "comunicação alternativa da mulher":

a) Cuestiona la condición femenina y las múltiples formas de opresión y discriminación que sufren las mujeres, y contribuye a los esfuerzos que se están dando por lograr un cambio.

b) Pretende recoger el malestar de las mujeres, su insatisfacción, sus contradicciones y sus angustias, no para canalizarlos hacia el consumo sino hacia una mayor lucidez que la mueva a participar críticamente en el logro de cambios en su beneficio y en beneficio de la sociedad.

c) Cuestiona el carácter "natural" de muchos de los roles femeninos y devela la injusta asignación de ellos según los sexos.

d) Puede considerarse feminista en la medida en cuanto se propone que la mujer sea protagonista de su destino: una mujer creadora, capaz de participar activamente y de mostrarse frente al hombre como un ser no subordinado ni inferior, sino su equivalente. Pretende darle dignidad a los roles femeninos y plantear la necesidad de que los hombres tenga la misma responsabilidad en ellos. Reivindica el derecho de las mujeres a integrarse en la sociedad en roles considerados tradicionalmente como masculinos y cuestiona los aspectos negativos de la cultura sexista. La comunicación alternativa postula la liberación de la mujer en el entendido que no es un proceso individual sino que está inserto en la lucha por lograr cambios sociales significativos a favor de las mayorías.

\footnotetext{
2 Disponível em:

http://www.unwomen.org/-/media/headquarters/attachments/sections/csw/bpa s final web.pdf?la=es\&vs=755

${ }^{3}$ Sally Burch (1996, p. 123) destaca o Programa de Apoio à Formação de Redes de Mulheres da Associação para o Progresso das Comunicações como um importante marco da experiência de Beijing: "El Programa [...] constituye una iniciativa piloto en esto sentido, por su capacidad de tomar en cuenta necesidades cambiantes de información y de formación de redes en la IV Conferencia Mundial sobre la Mujer. El programa creó espacios diferenciados por tema, región, lengua entre otros, alredor de los cuales las organizaciones implicadas en el proceso de Beijing - cualquiera fuese su nivel técnico de acceso - podían organizar, buscar información clave y compartir puntos de vista".
} 


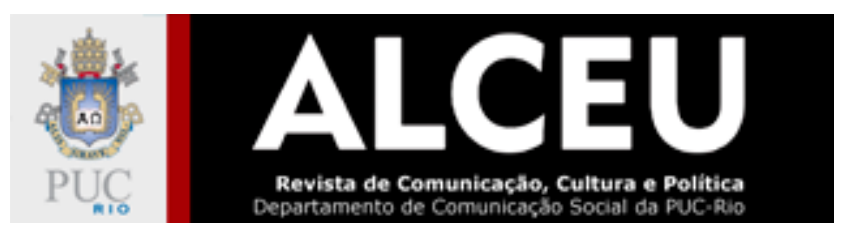

e) Quiere romper el flujo vertical característico de la información dominante para hacerlo más horizontal y participativo. En este sentido, es una comunicación que se plantea no sólo para la mujer sino, también, desde la mujer.

f) No se concibe a sí misma como una mercancía con fines de lucro sino como un servicio público, útil a la solución de problemas reales y necesarios en los esfuerzos por democratizar las comunicaciones. (1982, p. 02)

Percebem-se, no documento, preocupações que permanecem absolutamente atuais e necessárias, e que partem da crítica à imagem das mulheres na mídia e ao modo como os meios de comunicação hegemônicos constroem representações de gênero. Além disso, os parâmetros diferenciados para a mídia alternativa, traçados no documento, servem de referência para pensar o caráter de contraposição que consolida esta forma de comunicação no interior do movimento feminista.

Adriana Santa Cruz (1983, p. 83) analisa que a comunicação alternativa da mulher se apresenta como uma consciência crítica e criadora, a partir da ruptura que as mulheres fazem das 'amarras' que as afetam. "Es en este sentido donde la mujer tiene un papel, el cual adquiere toda su fuerza en la medida que nace de la conciencia que ella toma de la realidad que la rodea y su aporte posible al cambio".

Diversos foram os espaços de análise e proposição desenvolvidos pelo movimento feminista, em diversos países, que se dedicaram ao tema da comunicação (HASAN, GIL, 2016; MANO, 2017). Aparecem como preocupações questões como a inserção das demandas das mulheres na grande mídia e o acesso das mulheres aos meios de comunicação; a participação das mulheres no mercado da comunicação (MONTIEL, 2010; 2014; ROVETT GONEM, 2013); a inserção das demandas de gênero nas políticas de comunicação; o monitoramento da mídia, entre outros aspectos. Sobre este último, considera-se uma importante contribuição para 0 reconhecimento da necessidade de conhecer e superar a discriminação das mulheres nos meios.

Esta acción permitió sensibilizar a sectores de la opinión pública y, en algunos puntos, incluso logró modificar el comportamiento de ciertos medios, como también la adopción de ciertas políticas públicas para frenar los excesos. Sin embargo, los límites de estas estrategias se han hecho evidentes, pues en conjunto, poco ha cambiado. (BURCH, 2009, p. 14)

As conferências de mulheres e movimentos sociais afins (direitos humanos, LGBT+, igualdade racial, entre outros) trataram, de forma central ou tangencial, da questão da comunicação, principalmente a partir dos anos 1990 e nos primeiros anos do século XXI. As 
resoluções decorrentes destes espaços de articulação política evidenciam a importância da mídia nos processos de construção de representações sociais e sentidos identitários e apontam para a necessidade de uma comunicação democrática e plural.

Entre algumas experiências de mídia alternativa feminista, que representam possibilidades de utilização da comunicação para o fortalecimento do movimento e para a luta pela igualdade de gênero, destacam-se redes de comunicadoras e jornalistas feministas organizadas nos países da América Latina. Nas últimas décadas, registra-se a constituição de redes de comunicação com participação expressiva de mulheres vinculadas às lutas pela igualdade de gênero (SANTORO, 2007). Esse trabalho em rede embasa diferentes estratégias de inserção do debate de gênero na agenda social, com a incorporação gradativa das mídias digitais. A possibilidade de desierarquização e criação de modelos mais democráticos, de acordo com Miguel e Boix (2013, p. 55), caracteriza "o fator revolucionário, subversivo, transgressor que permite aspirar a pensar novos cenários e parece derivar-se intrinsecamente das possibilidades técnicas do espaço virtual e da rede".

Esse fenômeno tem origem na articulação de grupos de mulheres que, desde os anos 1990, passam a se apropriar das tecnologias como forma de luta política, o que acaba por motivar a criação de redes de jornalistas com visão de gênero (CHAER, 2007). Segundo dados apresentados por Hasan e Gil (2014), em 1993 se tem registro da criação do programa APC-Mujeres en Ecuador, dando origem às primeiras redes de mulheres na internet. Em 1995, o CIMAC impulsionou a criação de redes na América Latina, com a Red Nacional de Periodistas de México. En 1998, na Guatemala, é criada a Red de Mujeres Periodistas; em 2001, a Red Dominicana de Periodistas con Visión de Género; em 2003 a Red de Mujeres Periodistas de Nicaragua; em 2005 a Red Internacional de Periodistas con Visión de Género (RIPVG); em 2008, a Red Nacional de Mujeres Periodistas de Peru; e em 2009, a Red Colombiana de Periodistas con Visión de Género. A partir daí se multiplicam os fóruns de debate, listas de e-mails, sites de diversos coletivos, agências de notícias, blogs, revistas, webrádios, periódicos feministas, redes sociais e diversos outros espaços de difusão das demandas das mulheres.

Para Hasan e Gil (2014, p. 45), as redes de comunicação com enfoque de gênero "se ocuparon especialmente de destacar a las mujeres como sujetos de la información y la 
comunicación, sumándolas a la crítica por la explotación de las mujeres como objetos, en tanto imágenes o discursos circulantes por los medios". 4

De acordo com Sally Burch (2013, p. 118),

La participación democrática de las mujeres en los procesos comunicativos constituye una fuerza significativa para fortalecer el cambio, dotar de poder a las mujeres y promover la igualdad. El acceso equitativo de las mujeres en los medios masivos, redes alternativas, nuevas tecnologías de comunicación y, de manera global, en la distribución del "cyberespacio", es un elemento indispensable para garantizar la igualdad entre los géneros.

Entre as principais propostas de organizações de mulheres, no que se refere à comunicação, Burch $(2013$, p. 119) ressalta a promoção de um enfoque de gênero na comunicação, a eliminação de imagens degradantes de mulheres nos meios, o desenvolvimento de políticas de igualdade de gênero no mercado de trabalho, o uso da linguagem inclusiva e não sexista, a formação e a capacitação das mulheres na área da comunicação e a apropriação das tecnologias, entre outras.

Apropriar-se da mídia a partir de uma perspectiva voltada às demandas das mulheres representa a possibilidade de produção de discursos capazes de interferir na realidade. As práticas de comunicação se configuram, assim, como expressões de resistência que, ao produzirem outras subjetividades e projetarem projetos políticos coletivos, aproximam o ideal de transformação das desigualdades de gênero ao terreno das práticas cotidianas.

De acordo com Dafne S. Plou (2005, p. 174), a incorporação da perspectiva de gênero na comunicação se traduz na luta das mulheres pelo direito à palavra:

As mulheres ativistas estão lutando para assegurar que o gênero seja um princípio transversal quando forem discutidas políticas públicas e têm se comprometido a adotarem abordagens orientadas pelo gênero em todas as suas atividades, inclusive informações e comunicações. Elas encorajam a democratização dos processos políticos no interior de TIC, incluindo o uso de ferramentas de TIC para apoiar seus processos, assim como para formular e implementar uma política de TIC que use os princípios de abertura e participação justa. Essa participação coletiva no campo da comunicação é também elemento essencial para o fortalecimento e a autonomia das mulheres.

É necessário, portanto, pensar a comunicação como espaço estratégico de ação política. Afinal, é inegável reconhecer que os meios, na perspectiva feminista e de gênero, ajudam a

\footnotetext{
${ }^{4}$ Entre estas redes, destacam-se a CIMAC (Comunicación e Información de La Mujer), Red Informativa de Mujeres de Argentina, Periodistas de Argentina en Red por una Comunicación no Sexista, entre outras que atuam em nível nacional ou transnacional, produzindo conteúdos informativos em uma perspectiva de gênero.
} 
redescobrir formas de resistência, a denunciar opressões e desigualdades, a lançar o debate sobre questões que costumam ser ignoradas e a pautar o debate público.

\section{Movimento feminista e construção de redes}

Sabe-se que os movimentos sociais - entre eles, o feminismo - têm buscado novas estratégias de ação no campo da mídia, voltando-se para as redes digitais. A Internet tem se revelado uma importante ferramenta para divulgação de informações, visibilidade e articulação do movimento feminista, conforme se pode observar nos diversos sites, portais e blogs mantidos por organizações ou desenvolvidos a partir de uma perspectiva feminista. Sally Burch (1996, p. 120), ao discutir as potencialidades da Internet, avalia que "su naturaleza horizontal y descentralizada se adapta en forma ideal a las necesidades de las coordinadoras y redes de mujeres, las que se han convertido en una de las principales formas de articulación del movimiento de mujeres".

Referindo-se ao desafio das novas tecnologias para o movimento feminista, Burch observa que o processo necessário para que as mulheres convertam-se em atores sociais passa pela capacidade de gerar discursos (ou seja, desenvolver argumentos a favor da causa); dar legitimidade a esse discurso e, por fim, ganhar reconhecimento social (o que envolve a apropriação do discurso e sua projeção social). É neste sentido que o domínio das tecnologias constitui uma oportunidade e um desafio e tem sido colocado em pauta desde os anos 1990. Na análise da autora,

El acceso a la tecnología constituye sólo una parte del problema [de la exclusión]. Para las organizaciones de mujeres, hay también factores relacionados con la organización interna, la coordinación externa, el desarrollo de aptitudes en el manejo de la información, el compartir información, que pueden determinar cuán provechosa puede ser esta tecnología para una organización. (1996, p. 120)

Montsettat Boix, jornalista e coordenadora de Mujeres en Red5, ao discutir o poder da Internet e das tecnologías da informação para o ativismo social, observa que "el ciberfeminismo social está demostrando que las Nuevas Tecnologías de la Comunicación se convierten en aliadas

\footnotetext{
${ }^{5}$ Mujeres en Red é um portal de notícias que interliga mulheres de todo o mundo na luta pelos seus direitos. Disponível em: http://www.mujeresenred.net
} 
esenciales de activismo y suplementarias para las llamadas a la acción" (BOIX, 2002). A jornalista destaca as seguintes estratégias para fortalecer o uso da comunicação no movimento feminista:

- Formación para el acceso de las nuevas tecnologías a los sectores más desfavorecidos. Las mujeres merecen sin duda una atención especial.

- Utilización de las redes electrónicas para reforzar y consolidar grupos de acción.

- Establecimiento de redes mixtas. Creación de puentes entre quienes tienen acceso a Internet y quienes no lo tienen.

- Imperativo el desarrollo de estrategias de contenidos informativos. La contra-información con perspectiva de género y desde la reflexión feminista. Creación y mantenimiento de espacios propios de contra-información feminista y presencia de contenidos feministas en los movimientos críticos a la globalización neo-liberal. (BOIX, 2002)

Apropriar-se dos espaços de comunicação constitui, portanto, uma prática que se relaciona com a própria militância feminista. É o que se percebe nas formas de atuação de diferentes organizações de mulheres na América Latina e, principalmente, nas dinâmicas dos coletivos que surgiram de forma mais acentuada desde os anos 2000 e direcionam seu trabalho para as mobilizações e articulações em rede.

Nessa perspectiva, é importante destacar o ciberfeminismo radiofônico realizado por grupos e coletivos dedicados a promover a apropriação tecnológica nesse espaço, de modo a incentivar a produção de mulheres, em que se situam, entre diversas outras, iniciativas de grupos que integram a Asociación Latinoamericana de Educación Radiofónica (ALER) e o movimento de rádios livres.

No curso elaborado por RadiosLibres (2017), destaca-se uma discussão sobre as mulheres e a tecnologia, propostas para produções ciberfeministas em rádio e estratégias para combater o machismo na web.

Sigamos con este proceso de pensar cómo podemos convertirnos en radialistas ciberfeministas y construir un ciberfeminismo radiofónico. Se trata de que una vez por todas ocupemos los espacios técnicos (tanto en línea como desconectados), que agarremos los micrófonos, las grabadoras, que cortemos y peguemos, subamos y bajemos volúmenes y ganancias, y produzcamos nuestra radio: la de todas. Pero también se trata de ocupar el ámbito simbólico y apropiarnos de las palabras para que den sentido y construyan los mundos que queremos habitar. (RADIOSLIBRES, 2017, p. 19)

Verifica-se, assim, uma evidente diversificação de formatos e de estratégias de luta, diante do uso da internet como ferramenta para divulgação de informações e dispositivo capaz de dar visibilidade e servir como espaço de mobilização dos movimentos sociais. Trata-se de entender a inserção política no campo da mídia no contexto das disputas contra-hegemônicas. 
Hay una coincidencia en enfocar la actividad comunicacional como parte de la disputa contrahegemónica. En efecto, más allá de la transmisión o intercambio de información, los procesos de comunicación tienen una fuerte carga simbólica, están impregnados por los sistemas de representaciones y las imágenes de los actores sociales. De ahí que el campo de la comunicación sea considerado un espacio en disputa cultural, en donde se definen los sentidos de los proyectos sociales. (LEÓN, 2005, p. 94)

O ativismo no ambiente virtual promove a construção de novos padrões de autorrepresentação e viabiliza a participação política que acontece simultaneamente nos formatos on-line (ciberativismo) e off-line (movimentos de rua). "Temos agora um mundo permanentemente em rede em cada dimensão da experiência humana. As pessoas em suas redes evoluem conjuntamente em interações múltiplas e constantes" (CASTELLS, 2013, p. 173). Segundo Castells (2013), as mudanças envolvem processos de comunicação baseados em redes horizontais e interativas que possibilitam o compartilhamento de experiências e reivindicações, a ampliação das formas de sociabilidade e a construção de projetos alternativos.

Massimo di Felice (2013) destaca a simultaneidade nos movimentos nos espaços físicos e informativos e considera que se tratam de ações que se conectam no ambiente digital.

De fato, o termo ciberativismo origina-se nos anos 1990, com o advento das tecnologias digitais, e manifesta-se através de diversos movimentos. Esse tipo de ativismo midiático tem nas novas tecnologias de comunicação uma aliada valiosa para o fortalecimento das organizações, tanto local quanto globalmente, para a coordenação de campanhas e protestos, para a difusão de informações, denúncias e petições.

Todavia, o que constitui a característica própria do ciberativismo, ou ativismo online, não se resume à simples incorporação da internet aos processos comunicativos do ativismo, mas inclui a forma como essa tecnologia comunicativa transformou substancialmente o próprio ativismo e os conceitos de participação, espaço democrático, identidade coletiva e estratégia política, implicando em uma mudança significativa nas formas de ação social por parte dos movimentos ciberativistas (Mccaughey \& Ayers, 2003). (DI FELICE, 2013, p. 54)

Em toda América Latina, os movimentos de mulheres incorporaram os avanços das tecnologias, de forma mais acentuada com a evolução para a web $2.0^{6}$, marco para um processo

\footnotetext{
${ }^{6}$ De acordo com Massimo di Felice (2013, p. 58), "o advento da web 2.0 determina a passagem da mídia alternativa, isto é, das formas de uso e de produção de conteúdo alternativo disseminadas nos diversos âmbitos contraculturais, para a mídia participativa, ou seja, as formas sociais digitais que articulam suas arquiteturas através do diálogo e do compartilhamento de conteúdos. (...) O que marca a terceira fase do ativismo não é apenas a sua expansão em nível planetário e a inauguração de uma nova forma de protagonismo tecnosocial, na qual a dimensão político-democrática desloca-se dos espaços tradicionais para as redes interativas digitais, mas, sobretudo, a consolidação de algumas formas expressivas, que no decorrer da última década delinearam tais particulares formas de ação".
} 


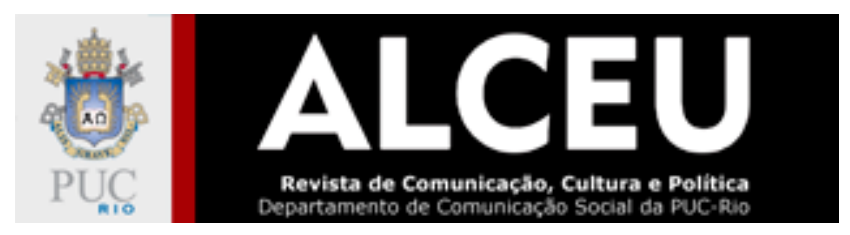

mais horizontal e participativo de comunicação que se potencializou em meio à ação de diversos movimentos. Assim, pode-se dizer que a comunicação no ambiente da web, iniciada a partir de demandas do movimento de mulheres pautadas em diversas conferências e documentos, tem representado um espaço de atuação política que se consolida nas últimas três décadas e continua a apresentar desafios para a militância feminista na atualidade.

Karina Janz Woitowicz Professora de Jornalismo da Universidade Estadual de Ponta Grossa (UEPG/PR) Doutorado Interdisciplinar em Ciências Humanas / UFSC ORCID: https://orcid.org/0000-0002-7644-8560 E-mail:karinajw@gmail.com

Recebido em: 9 de maio de 2019.

Aprovado em: 23 de julho de 2019.

\section{Referências}

BOIX, Montserrat. "Sociedad civil y redes de mujeres en las nuevas tecnologías de la comunicación". Intervención realizada en las Jornadas "Mujeres y Nuevas Tecnologías", organizadas por la UNED - 10 mayo 2002.

BURCH, Sally. Comunicación, organización y género. Ellas tienen la palabra. Área Mujeres ALAI Materiales para la formación 1. Quito: ALAI, 2009.

BURCH, Sally. "El reto de las nuevas tecnologías". In: PORTUGAL, Ana Maria; TORRES, Carmen (editoras). Por todos los medios: Comunicación y Género. Ediciones de las Mujeres n. 23. Santiago de Chile: Isis Internacional, 1996. p.117-124.

BURCH, Sally. Movimiento de mujeres: La comunicación con enfoque de género. In: LEÓN, Osvaldo (coord.). Democratizar la palabra: Movimientos convergentes en comunicación. Quito: Agencia Latinoamericana de Información, 2013. P. 117-120.

CASTELLS, Manuel. Redes de indignação e esperança: movimentos sociais na era da internet. Rio de Janeiro: Zahar, 2013.

CERQUEIRA, Carla; RIBEIRO, Luísa Teresa; CABECINHAS, Rosa. Mulheres \& Blogosfera: contributo para o estudo da presença feminina na "rede". Ex aequo, 2009, n.19, pp. 111-128. Disponível em: http://www.scielo.mec.pt/pdf/aeg/n19/n19a10.pdf. 


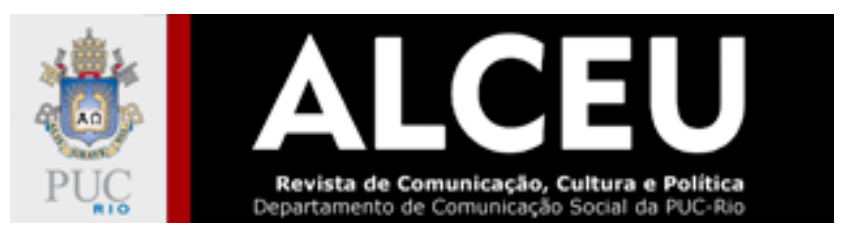

CHAHER, Sandra. Medios masivos/ medios alternativos y redes de periodistas. In: CHAHER, Sandra; SANTORO, Sonia (orgs.). Las palabras tienen sexo: introducción a un periodismo con perspectiva de género. Buenos Aires: Artemisa Comunicación Ediciones, 2007. p. 111-124.

DI FELICE, Massimo. Ser redes: o formismo digital dos movimentos net-ativistas. Matrizes, ano 7, n. 2, jul./dez. 2013. P. 49-71. Disponível em: https://www.revistas.usp.br/matrizes/article/view/69406

HASAN, Valeria F.; GIL, Ana Soledad. La comunicación con enfoque de género, herramienta teórica y acción política. Medios, agenda feminista y prácticas comunicacionales. El caso de Argentina. La ventana, Guadalajara, v. 5, n. 43, p. 246-280, jun. 2016. Disponível em: http://www.scielo.org.mx/scielo.php?script=sci arttext\&pid=S1405-94362016000100246\&lng=es\&nrm=iso.

LEÓN, Osvaldo (cord.). Movimientos sociales y comunicación. Quito: Agencia Latinoamericana de Información - ALAI, 2005.

MANO, Maíra Kubík T. De um jornalismo sexista a um jornalismo com perspectiva de gênero. Lutas Sociais, São Paulo, vol.21 n.39, p.9-20, jul./dez. 2017. Disponivel em: https://revistas.pucsp.br/index.php/ls/article/view/35874

MÁRQUEZ, María Cruz Tornay. Comunicación, subalternidad y género: experiencias comunicativas comunitarias de mujeres afrodescendientes e indígenas en América Latina. Tesis doctoral. Sevilla, Universidad de Sevilla, 2017.

MIGUEL, Ana de; BOIX, Montserrat. Os gêneros da rede: os ciberfeminismos. In: NATANSOHN, Graciela. Internet em código feminino: teorias e práticas. Buenos Aires: La Crujia, 2013. p. 37-73.

MONTIEL, Aimée Vega. Igualdad de género, poder y comunicación: las mujeres en la propiedad, dirección y puestos de toma de decisión. La Ventana, n. 40, 2014. P. 186-212.

. Las mujeres y el derecho humano a la comunicación: su acceso y participación en la industria mediática. Revista Mexicana de Ciencias Políticas y Sociales, vol. LII, núm. 208, enero-abril, 2010, pp. 81-95.

NATANSOHN, Graciela. Que têm a ver as tecnologias digitais com o gênero? In: Internet em código feminino: teorias e práticas. Buenos Aires: La Crujia, 2013. p. 15-38.

PLOU, Dafne Sabanes. "E as questões de gênero na sociedade da informação?" In: MELO, José Marques; SATHLER, Luciano (orgs.). Direitos à comunicação na Sociedade da Informação. São Bernardo do Campo: UMESP, 2005. p. 153-179.

RADIOS LIBRES. Ciberfeminismo radiofónico: ocupar la radio para convertirla en nuestra aliada. RadiosLibres. Curso virtual n. 19, julio 2017. Disponível em: https://radioslibres.net/wpcontent/uploads/media/uploads/documentos/tutorial 19 ciberfeminismo radiofonico.pdf

ROVETT GONEM, Florencia. Percepciones sobre desigualdades de género en el trabajo periodístico. Global Media Journal, vol. 10, núm. 20, 2013, pp. 54-73.

SANTA CRUZ, Adriana; ERAZO, Viviana. Reflexiones en torno a la comunicación alternativa de la mujer. México: Instituto Latinoamericano de Estudios Transnacionales (ILET), 1982. 


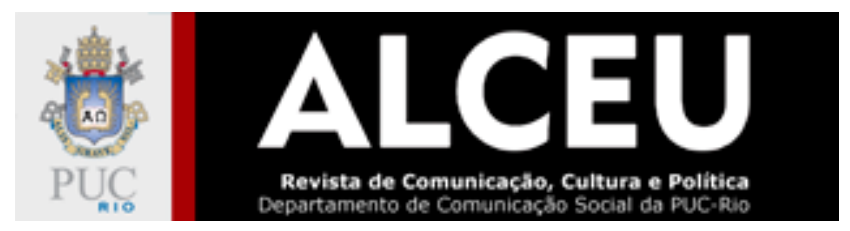

SANTA CRUZ, Adriana. "Mujer y comunicación: nuevas voces en la búsqueda de una democracia auténtica". In: MATTA, Fernando Reyes. Comunicación alternativa y búsquedas democráticas. México: ILET Instituto Latinoamericano de Estudios Transnacionales, 1983. p. 71-85.

SANTORO, Sonia. La práctica del periodismo de género. In: CHAHER, Sandra; SANTORO, Sonia (orgs.). Las palabras tienen sexo: introducción a un periodismo con perspectiva de género. Buenos Aires: Artemisa Comunicación Ediciones, 2007. p. 137-152.

\section{Resumo}

O artigo propõe uma (re)leitura do processo organizativo do movimento feminista na América Latina a partir da apropriação da internet e das ferramentas tecnológicas para a constituição de redes de comunicação e para o fortalecimento do ativismo em torno dos direitos das mulheres. Para tanto, utiliza uma revisão bibliográfica focada nos direitos das mulheres à comunicação e documentos que demarcam o debate acerca da necessidade de difundir conteúdos alternativos e fortalecer as vozes das mulheres como sujeitos políticos, tendo como marco as iniciativas promovidas desde os anos 1990 acerca do uso da comunicação para diminuir as desigualdades de gênero. Ao longo do texto, busca-se recuperar o debate sobre as estratégias de militância feminista articuladas com o campo midiático, de modo a dialogar com as lutas históricas das mulheres por direitos e com as demandas e desafios do presente.

Palavras-chave: mídia alternativa; redes de comunicação; movimento feminista e de mulheres; tecnologias; gênero.

\section{Abstract}

The article proposes a (re)reading of the organizational process of the feminist movement in Latin America from the appropriation of the internet and the technological tools for the creation of communication networks and for the strengthening of activism around the rights of women. To this end, it uses a literature review focused on women's rights to communication and documents that demarcate the debate about the need to disseminate alternative contents and strengthen women's voices as political subjects, based on the initiatives promoted since the 1990s on the use communication to reduce gender inequalities. Throughout the text, the aim is to recover the debate about the strategies of feminist militancy articulated with the media field, in order to dialogue with the historical struggles of women for rights and with the demands and challenges of the present.

Keywords: alternative media; communication networks; women's and women's movement; technologies; gender.

\section{Resúmen}

El artículo propone una (re)lectura del proceso organizativo del movimiento feminista en América Latina a través de la apropiación de internet y herramientas tecnológicas para el establecimiento de 


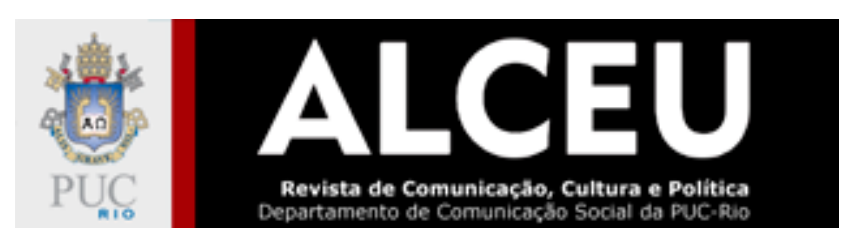

redes de comunicación y el fortalecimiento del activismo en torno a los derechos de las mujeres. Para ello, utiliza una revisión bibliográfica centrada en los derechos de las mujeres a la comunicación y documentos que marcan el debate sobre la necesidad de difundir contenidos alternativos y fortalecer las voces de las mujeres como sujetos políticos, en el marco de las iniciativas promovidas desde la década de 1990 sobre el uso de la comunicación para reducir las desigualdades de género. A lo largo del texto, buscamos recuperar el debate sobre las estrategias de militancia feminista articuladas con el campo de los medios, a fin de dialogar con las luchas históricas de las mujeres por los derechos y con las demandas y desafíos del presente.

Palavras clabe: medios alternativos; redes de comunicación; movimiento feminista y de mujeres; tecnologías; género. 